\title{
USE OF NOVEL CASING IN SUCUK PRODUCTION: ANTIMICROBIALS INCORPORATED INTO MULTILAYER PLASTIC FILM
}

\author{
Y. ÇeleBi SeZer ${ }^{a *}$ and H. BozKurT ${ }^{b}$

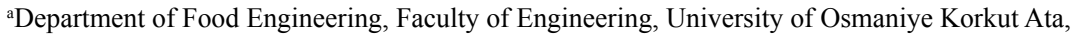 \\ Karacaoglan Campus, 80000, Osmaniye. Turkey \\ ${ }^{b}$ Department of Food Engineering, Faculty of Engineering, University of Gaziantep, University Avenue, \\ 27310 Gaziantep. Turkey.
}

(Received: 6 November 2017; accepted 26 December 2017)

\begin{abstract}
In this study, effects of novel casing, antimicrobials (chitosan and AgZeo) incorporated into multilayer polyethylene casing, on chemical and microbial attributes of sucuks were followed through 3 days of fermentation and 12 days of storage after heat treatment. Microbial growth was reduced by chitosan incorporated casing. Aerobic plate count (APC) of $8.81 \log \mathrm{CFU} \mathrm{g}{ }^{-1}$ on the $3^{\text {rd }}$ day of fermentation was reduced to $2.60 \log \mathrm{CFU} \mathrm{g}^{-1}$ by the end of storage. APC and lactic acid bacteria $(\mathrm{LAB})$ were decreased significantly $(\mathrm{P}<0.05)$ by antimicrobial casings. The lowest concentrations of histamine and tyramine were observed $(\mathrm{P}<0.05)$ in sucuks stuffed into chitosan incorporated casing. These results show that antimicrobial casing could be used in sucuk production to improve its safety and quality.
\end{abstract}

Keywords: heat treated sucuks, active casings, antimicrobial casing

Antimicrobial package is one of the main applications of active packaging (JOERGER, 2007). Growth of pathogenic and spoilage microorganisms is restricted by incorporation of antimicrobials into film. Antimicrobials in active package systems may lose their activities slowly during the storage period (IsHITANI, 1995). Chitosan has antimicrobial spectrum against $\mathrm{G}(+) / \mathrm{G}(-)$ bacteria, moulds, and yeasts (Soysal et al., 2015). One of the most commonly incorporated antimicrobial agents into plastics is silver substituted zeolite (AgZeo). High antimicrobial activities of Ag-ions are due to inactivation of series of metabolic enzymes (KerRY et al., 2006).

Sucuk, a traditional Turkish type fermented sausage, is widely consumed in Turkey and Middle East Region of Asia. Sucuks are sensitive to lipid oxidation and microbial growth, which cause development of rancid flavour and microbial spoilage (BozKURT, 2006). In the recent years, heat treatment has become one of the important steps of sucuk production, even though heat treatment is not part of traditional sucuk manufacturing (ERCoşKUN et al., 2010). Hence, multilayer films as a casing, containing antimicrobial substances will be good choice for preventing microbial growth and extending shelf life for products such as sucuks (SoYSAL et al., 2015).

To our best knowledge, until today, no papers were published about the inhibitory action of antimicrobial agents (AgZeo and chitosan) incorporating casings on the microbial growth and biogenic amines formation in sucuks. In this study, the effectiveness of plastic casings

\footnotetext{
* To whom correspondence should be addressed.

Phone: +903288271000; fax: +903288250097; e-mail: yasemincelebi@osmaniye.edu.tr
} 
(multilayered active film LDPE + Antimicrobial/PA/LDPE) produced by incorporation of antimicrobial agents, such as chitosan and AgZeo, into polyethylene (PE) layer was investigated. The purpose of this study was to evaluate the effectiveness of multilayered active film in improving the microbial and selected chemical characteristics of sucuks during fermentation and storage after heat treatment. Also, control groups composed of multilayer casing without antimicrobial compounds and collagen casing were prepared for comparison.

\section{Materials and methods}

\subsection{Materials}

The polymers were fabricated by NAKSAN Plastic Company (Gaziantep, Turkey) as incorporation of active compounds into food contact surface of multilayer film. Silver substituted zeolite and chitosan were provided by Handary SA and Aldrich Chemical Company, Inc., USA, respectively.

Fresh boneless lamb meat (shoulder) and beef meat (whole brisket), spices, tail fat, sugar, salt, commercial virgin olive oil, and artificial collagen casing were purchased from Coskoy Company in Osmaniye. A mixture of Lactobacillus plantarum, Staphylococcus xylosus, Staphylococcus carnosus, and Pediococcus pentosaceus obtained from Biocarna (Wiesby, Germany) was used as starter culture.

\subsection{Film preparation}

All multilayer casings were manufactured by NAKSAN Plastic Company. About $2 \%$ antimicrobial compound, ethylene vinyl acetate copolymer (EVA; used to give elasticity and porous structure to the film), and $94 \%$ low density polyethylene were mixed by using twin screw extruder (Rondol, UK) for production of active master batches. The control (LDPEpolyamide-LDPE) and multilayer active casings (LDPE+Antimicrobial-polyamide-LDPE) having the identical thicknesses $(70 \mathrm{~mm})$ were fabricated by blown film extruder (SoYSAL et. al., 2015). Orevac was used as tie layer in both control and active multilayer film production. Finally, the films were sealed to the size of artificial collagen casing for stuffing of sucuk batter.

\subsection{Sucuk preparation}

Sucuks were produced in Coskoy Food Company (Osmaniye). Beef, lamb, tail fat, clean garlic, salt, spices, olive oil, sugar, and starter culture were used for sucuk batter by the following recipe: $450 \mathrm{~g}$ beef (about $6 \%$ fat), $450 \mathrm{~g}$ lamb (about $8 \%$ fat), $200 \mathrm{~g}$ tail fat, $20.76 \mathrm{~g}$ garlic, $18 \mathrm{~g}$ salt, $11.42 \mathrm{~g}$ allspice, $11 \mathrm{~g}$ red pepper, $5.5 \mathrm{~g}$ black pepper, $5.5 \mathrm{~g}$ cumin, $4.4 \mathrm{~g}$ sugar, $2.1 \mathrm{~g}$ olive oil, $1.1 \mathrm{~g}$ cinnamon, and $0.48 \mathrm{~g}$ clove. One hundred $\mathrm{mg} \mathrm{kg}^{-1}$ nitrate and $50 \mathrm{mg} \mathrm{kg}^{-1}$ nitrite were used as curing agents. Beef and lamb were chopped in a cutter (OEM, $750 \mathrm{~W}$, China), other ingredients, except tail fat, were added during chopping of meat in a cutter for $15 \mathrm{~min}$ at $4{ }^{\circ} \mathrm{C}$. During the kneading, starter culture mixture was also added as $20 \mathrm{~g}$ commercial culture mixture $/ 100 \mathrm{~kg}$ of meat. Sucuk batter was rested at $0-4{ }^{\circ} \mathrm{C}$ for $12 \mathrm{~h}$, than the chopped refrigerated tail fat was mixed into the sucuk batter in a cutter. After that, batter was stuffed into artificial collagen casings (35 Q, Yildiz Food Company, Turkey) of $38 \mathrm{~mm}$ diameter, control multilayer plastic casings, and multilayer antimicrobial plastic casings under hygienic 
status using a filling machine (Xiaojin, GZY3600, China) at $4{ }^{\circ} \mathrm{C}$ (BozkuRT, 2007). Twentyfour sausages, each about $100 \mathrm{~g}$ in weight, were prepared with each casing.

Samples were fermented for 3 days at $22{ }^{\circ} \mathrm{C}$, after that they were heated until the core temperature reached $70{ }^{\circ} \mathrm{C}$ and held at that temperature for $5 \mathrm{~min}$ in an oven (Charan, $\mathrm{KBO}$ 3000 , Turkey). Then, obtained sucuks were stored at $18^{\circ} \mathrm{C}$ for 12 days.

\subsection{Sampling and sample preparation}

Two samples of sucuks were taken from each batch on the $0^{\text {th }}$ and $3^{\text {th }}$ days of fermentation for analysis. After fermentation, samples were taken from heat treated sucuks starting from the $0^{\text {th }}$ day with the interval of 3 days as $3^{\text {th }}, 6^{\text {th }}$, $9^{\text {th }}$, and $12^{\text {th }}$ days of fermentation. The aerobic plate counts (APC), lactic acid bacteria counts (LAB), and biogenic amine contents of samples were determined. All experiments were performed in duplicate. A $25 \mathrm{~g}$ of sucuk sample was homogenized in a stomacher bag containing $225 \mathrm{ml} 0.1 \%$ peptone water for microbiological analysis (BOzKURT \& ERKMEN, 2002). Remaining samples were cut into small pieces (about $5 \times 5 \times 5 \mathrm{~mm}$ ), and $50 \mathrm{~g}$ was homogenized using a Waring blender for biogenic amines analyses, then was stored frozen $\left(-20^{\circ} \mathrm{C}\right)$ up to analysis time.

\subsection{Microbiological analysis}

APCs were performed as the Spread Plate Method on aerobic Plate Count Agar (Merck, Darmstadt, Germany). The counts of LAB were determined by the Spread Plate Method on MRS agar (Merck, Darmstadt, Germany) (ERKMEN, 2000).

\subsection{Determination of biogenic amines}

The contents of biogenic amines were examined using a chromatographic method (BozKURT \& ERKMEN, 2002). The HPLC system had a quadratic gradient pump (Ultimate, 3000 Pump), anionex Ultimate 3000 diode array detector, an Ultimate 3000 column compartment, and a computer containing a Chromeleon package program and the HPLC column was Spherisorb ODS2, $10 \mu \mathrm{m}, 200 \mathrm{~mm} \times 4.60 \mathrm{~mm}$ (Phenomenex, Torrance, CA, US).

\subsection{Statistical analysis}

A one-way ANOVA was applied for biogenic amine formation and microbiological count values as a function of time or different casings to detect significant differences at $\mathrm{P}<0.05$ using the SPSS version 18.0 (SPSS Inc., Chicago, IL, USA). Duncan's multiple range test was performed on the different antimicrobial casings during fermentation and storage.

\section{Results and discussion}

\subsection{Microbiological changes}

Changes in APC and LAB (log CFU g ${ }^{-1}$ ) counts of sucuks with antimicrobial (chitosan and AgZeo), control, and collagen casings were followed during fermentation and storage periods, and their results following the heat treatment are shown in Figures 1 and 2, respectively. To detect the effectiveness of antimicrobial casings on APC and LAB, statistical analyses were carried out. APC and LAB counts in sucuks increased $(\mathrm{P}<0.05)$ during the 3 days of fermentation because of the high $\mathrm{RH}(85-95 \%)$ and optimum temperature $\left(22^{\circ} \mathrm{C}\right)$ for 
microbial growth. The lowest APC and LAB counts were found in sucuks stuffed into active casings. Microbial growth was the slowest in chitosan casing, where the aerobic plate count was of $8.81 \log \mathrm{CFU} \mathrm{g}{ }^{-1}$, and $\mathrm{LAB}$ count $7.57 \log \mathrm{CFU} \mathrm{g}^{-1}$ at the end of the fermentation period. After heat treatment, APCs were reduced to a range of 2.60 and $4.26 \log \mathrm{CFU} \mathrm{g}^{-1}$, while $\mathrm{LAB}$ counts varied from 2.38 to $3.97 \log _{\mathrm{CFU} \mathrm{g}}{ }^{-1}(\mathrm{P}<0.05)$. Higher reductions in APC and $L A B$ values were found during storage in sucuks stuffed into AgZeo and chitosan casings. Similarly, several authors reported that chitosan and AgZeo have antimicrobial activities against fungi, yeasts, and bacteria (Aymerich et al., 2008; Soysal et al., 2015). The antimicrobial property of chitosan is probably due to the interaction of the positively charged chitosan with negatively charged debris on the cell surface of numerous fungi and bacteria, inducing change in wide cell surface and changing cell permeability (PARK et al., 2010; SoYSAL et al., 2015). PARK and co-workers (2010) reported that chitosan could migrate from LDPE films to inhibit bacteria. They also concluded that if the concentration of chitosan is higher than $1.4 \%$, both Gram (+) and Gram (-) bacteria are constricted. BOLUDA-AguILAR and co-workers (2010) studied fresh loin packed with zeolite bags including an antimicrobial agent (essential oil of thyme). They reported that during 3 weeks of storage, zeolite and thyme caused a reduction in microbial count of $2 \log \mathrm{CFU} \mathrm{g}{ }^{-1}$ compared to control. It was determined in many studies that reductions in APC and LAB levels were about 3-5 logs order after heat treatment (DALMIS \& SOYER, 2008; ERÇOŞKUN et al., 2010). Our results were similar to that of other authors for APC and LAB, who showed that LAB and APC increased during the fermentation and were reduced after heat treatment (BOzKURT, 2004; ERÇoşKUN et al., 2010).

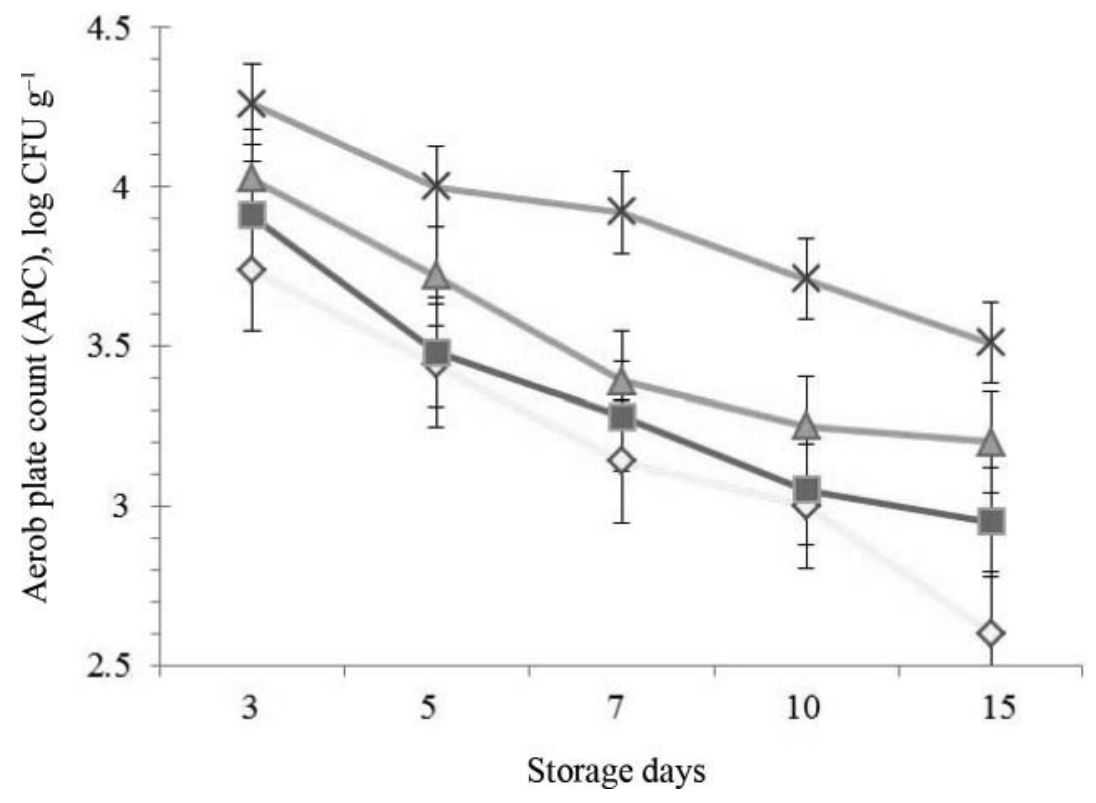

Fig. 1. Changes in APC of sucuks during storage

Chitosan; —-: Ag-zeo; $\longrightarrow$ - : Control; $\rightarrow$ * : Collagen case 


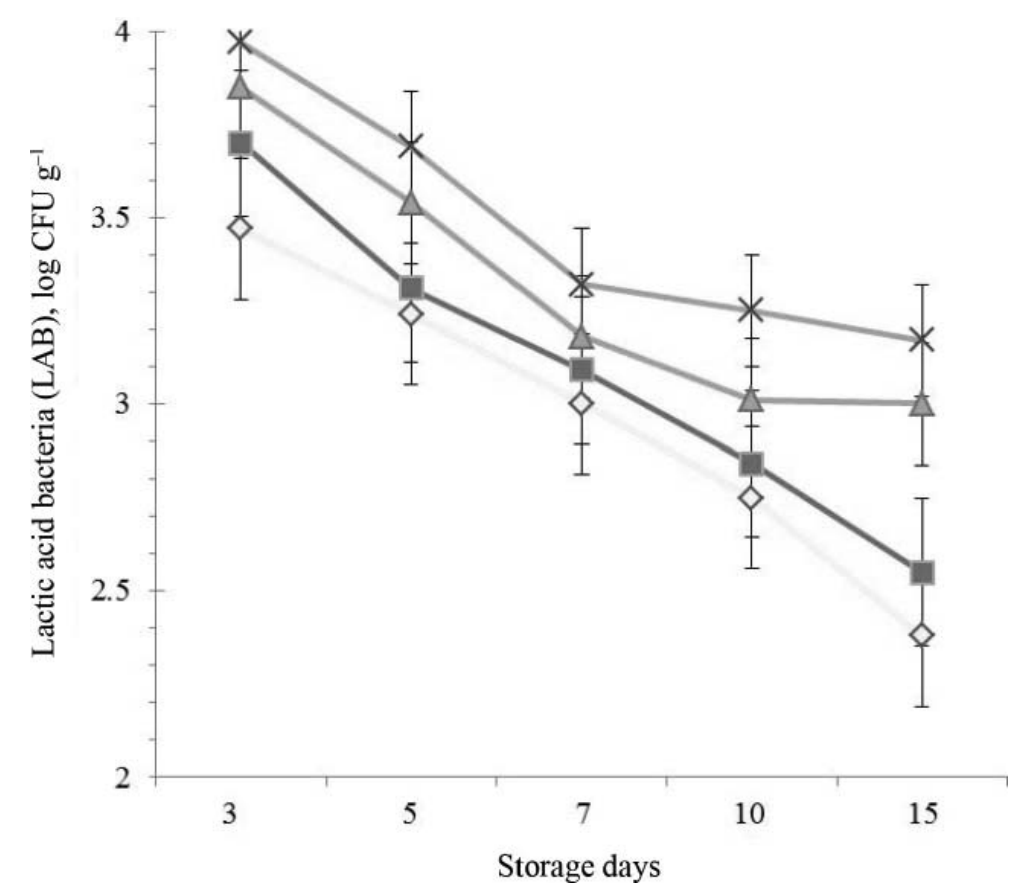

Fig. 2. Changes in LAB numbers of sucuks during storage

: Chitosan; $\rightarrow-:$ : Ag-zeo; $\longrightarrow$ : Control; $\longrightarrow$ * Collagen case

\subsection{Biogenic amine formation}

Table 1 shows the contents of putrescine (PUT), histamine (HIS), and tyramine (TYR) in the sucuk during fermentation and storage.

Fermentation time and incorporation of chitosan and AgZeo into casings affect $(\mathrm{P}<0.05)$ the concentration of putrescine. Putrescine content increased gradually $(\mathrm{P}<0.01)$ from $33 \mathrm{mg} \mathrm{kg}^{-1}$ to $220.92 \mathrm{mg} \mathrm{kg}^{-1}$ during the 3 days of fermentation (Table 1). Similarly, BozKURT (2006) found that the formation of putrescine in sucuks increased gradually up to $159.76 \mathrm{mg}$ $\mathrm{kg}^{-1}$ during the first 6 days of the fermentation. The highest putrescine content was found $(\mathrm{P}<0.05)$ in sucuk stuffed into collagen casing, while the lowest was in sucuk stuffed into chitosan incorporated casing at the end of fermentation. At the same time, putrescine levels of the samples stuffed into chitosan and $\mathrm{AgZeO}$ incorporated casings were not different from each other $(\mathrm{P}>0.05)$ during storage. Putrescine formation was reduced $(\mathrm{P}<0.05)$ by incorporation of active agents during storage. Several researchers have found that the concentration of putrescine is associated with the total aerobic viable count (BOZKURT, 2006; KURT \& ZORBA, 2010). Moreover, putrescine formation is related with growth of aerobic bacteria, Enterobacter spp., and some lactic acid bacteria (BOvER-CiD et al., 2001; KURT \& ZORBA, 2010). SIROCCHI and coworkers (2013) studied the effects of essential oils of Rosmarinus officinalis incorporated into high density polyethylene on the formation of biogenic amine in fresh meat. While putrescine concentration of meat in active packaging (AP) was $33.1 \mathrm{mg} \mathrm{kg}^{-1}$, its concentration in polycoupled packaging (PP) was 62.3 at the end of the first 7 fermentation days. 


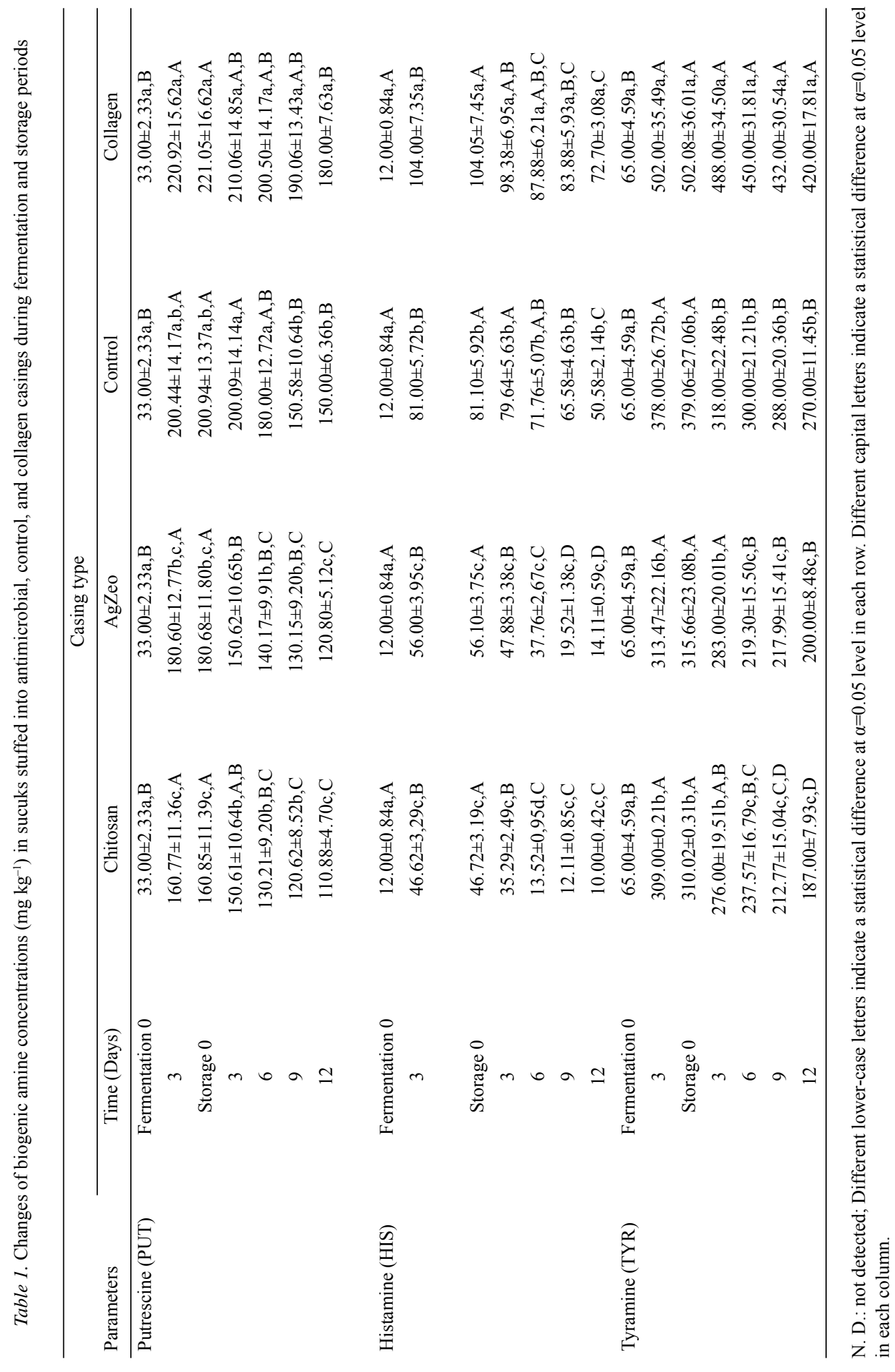


Histamine concentration was affected by the time of fermentation and the use of different antimicrobial casings $(\mathrm{P}<0.05)$. At start, sucuk batter had $12 \mathrm{mg} \mathrm{kg}^{-1}$ histamine content (Table 1). This amount increased $(\mathrm{P}<0.05)$ to $46.63 \mathrm{mg} \mathrm{kg}^{-1}$ and $104.00 \mathrm{mg} \mathrm{kg}^{-1}$ during the fermentation in sucuks stuffed into chitosan and collagen casings, respectively (Table 1). Similarly, RUIZ-CAPILLAS and JiMENEZ-COLMENERO (2005) and BOZKURT and co-workers (2006) found that the histamine formation in sausages increased during the first days of fermentation. The highest histamine concentration was observed $(\mathrm{P}<0.05)$ in sucuk stuffed into collagen casing, while the lowest level was in sucuk stuffed into chitosan casing, both at the end of fermentation and storage. Histamine concentrations decreased $(\mathrm{P}<0.01)$ in sucuks stuffed into active casing and control plastic casing during storage. Generally, histamine levels of the samples stuffed into chitosan and $\mathrm{AgZeO}$ casings were not different from each other $(\mathrm{P}>0.05)$ during fermentation and storage (Table 1). Nout (1994) reported the maximum allowable histamine contents for sausages ranged from 50 to $100 \mathrm{mg} \mathrm{kg}^{-1}$. In this study, histamine content was found within this range during both fermentation and storage. SIROCCHI and coworkers (2013) studied the performances of the new active packaging system (AP) with addition of essential oils of $R$. officinalis at $4 \% \mathrm{w} / \mathrm{w}$ on chicken meat. They reported that histamine level of chicken meat in active package was lower than that in poly-coupled packaging (PP) system stored at $4{ }^{\circ} \mathrm{C}$.

Fermentation time and use of active casings had an important effect $(\mathrm{P}<0.05)$ on tyramine formation. Its concentration increased $(\mathrm{P}<0.01)$ to $502 \mathrm{mg} \mathrm{kg}^{-1}$ at the end of the fermentation (Table 1). KURT \& ZORBA (2010) found that tyramine content increased in the first days of the fermentation. Some researchers (BOVER-CiD et al., 2001) reported that tyramine formation increased due to the activity of lactic acid bacteria. Additionally, the total aerobic viable count could also influence tyramine concentration (PöTZELBERGER et al., 1997). At the same time, tyramine content of the samples stuffed into active and control casings were different from samples stuffed into collagen casing $(\mathrm{P}<0.05)$ at the end of the fermentation (Table 1). VINCI and ANTONELLI (2002) reported that tyramine formation in red meat rose during 36 days of storage at $4{ }^{\circ} \mathrm{C}$. In this study, using antimicrobial casings, the tyramine formation decreased $(\mathrm{P}<0.05)$ during storage. The highest tyramine content was found in the collagen casing and the lowest in the chitosan casing with values of about 420 and $187 \mathrm{mg} \mathrm{kg}^{-1}$, respectively. The permissible maximum level of tyramine in foods is 100 $800 \mathrm{mg} \mathrm{kg}^{-1}$, and $1080 \mathrm{mg} \mathrm{kg}^{-1}$ tyramine is toxic (Shalaby, 1996). In this work, tyramine levels of samples were below this level.

\section{Conclusions}

In this study, a new active casing system for heat treated sucuks was developed formulated with chitosan and AgZeo for improving quality attributes during the fermentation and storage time. The results of this work indicated that the use of active casings reduced APC and numbers of LAB when compared with the control. Antimicrobial plastic casings including chitosan and AgZeo decreased $(\mathrm{P}<0.05)$ putrescine, histamine, and tyramine formation in sucuks. So, these antimicrobial casings could be used for sucuk production to improve quality and ensure safer products. 


\section{References}

Aymerich, T., Picouet, P.A. \& Monfort, J.M. (2008): Decontamination technologies for meat products. Meat Sci., 78, 114-129.

Boluda-Aguilar, M., Gómez-López, A., Marín-Iniesta, F. \& Taboada-Rodríguez, A. (2010): Antimicrobial active packaging for meat products. -in: Fito, P. \& ToldRA, F. (Eds) Proceedings of international conference on food innovation "FoodInnova 2010", Universidad Politécnica de Valencia, Valencia, Spain, 25-29 Oct. 2010, 4 pages.

Bover-Cid, S., Miguélez-Arrizado, M.J. \& Vidal-Carou, M.C. (2001): Biogenic amine accumulation in ripened sausages affected by the addition of sodium sulphite. Meat Sci., 59, 391-396.

Bozkurt, H. \& ERKmen, O. (2002): Effects of starter cultures and additives on the quality of Turkish style sausage (sucuk). Meat Sci., 61, 149-156.

Bozkurt, H. \& ERKmen, O. (2004): Effect of nitrate/nitrite on the quality of sausage (sucuk) during ripening and storage. J. Sci. Food Agr., 84, 279-286.

Bozkurt, H. (2006): Utilization of natural antioxidants: Green tea extract and Thymbra spicata oil in Turkish dryfermented sausage. Meat Sci., 73, 442-450.

Bozkurt, H. (2007): Comparison of the effects of sesame and Thymbra spicata oil during the manufacturing of Turkish dry-fermented sausage. Food Control, 18(2), 149-156.

Dalmiş, U. \& Soyer, A. (2008): Effect of processing methods and starter culture (Staphylococcus xylosus and Pediococcus pentosaceus) on proteolytic changes in Turkish sausages (sucuk) during ripening and storage. Meat Sci., 80, 345-354.

ErcoşKun, H., TAĞI, Ş. \& ERTAȘ, A.H. (2010): The effect of different fermentation intervals on the quality characteristics of heat-treated and traditional sucuks. Meat Sci., 85, 174-181.

ERKmen, O. (2000): Basic methods for the microbiological analysis of foods. Gaziantep, Turkey: University of Gaziantep Press, 564 pages.

IshitAni, T. (1995): Active packaging for food quality preservation in Japan. -in: AcKermann, P., JAGERSTAD, M. \& Ohlsson, Tн. (Eds), Food and food packaging materials chemical interactions. Royal Society of Chemistry, Cambridge. pp. 177-188.

Joerger, R.D. (2007): Antimicrobial films for food applications: A quantitative analysis of their effectiveness. Packag. Technol. Sci., 20(4), 231-273.

Kerry, J.P., O'Grady, M.N. \& Hogan, S.A. (2006): Past, current and potential utilization of active and intelligent packaging systems for meat and muscle-based products: A review. Meat Sci., 74, 113-130.

KurT, S. \& Zorba, Ö. (2010): Biogenic amine formation in Turkish dry fermented sausage (sucuk) as affected by nisin and nitrite. J. Sci. Food Agr., 90(15), 2669-2674.

Nout, M.J.R. (1994): Fermented foods and food safety. Food Res. Int., 27(3), 291-298.

PARK, S.I., MARsh, K.S. \& DAwson, P. (2010): Application of chitosan-incorporated LDPE film to sliced fresh red meats for shelf life extension. Meat Sci., 85, 493-499.

Pötzelberger, D.E., Paulsen, P., Hellwig, E. \& Bauer, F. (1997): Investigations on shelf life and shelf life assessment of raw meat: Formation of biogenic amines and microbial changes during storage. Fleischwirtschaft, 77(2), 1086-1089.

Ruiz-CAPillas, C. \& JimÉnez-Colmenero, F. (2005): Biogenic amines in meat and meat products. Crit. Rev. Food Sci. Nutr., 44(7-8), 489-599.

Shalaby, A.R. (1996): Significance of biogenic amines to food safety and human health. Food Res. Int., 29, 675690.

Sirocchi, V., Caprioli, G., Cecchini, C., Coman, M.M., Cresci, A., Maggi, F. \& Sagratini, G. (2013): Biogenic amines as freshness index of meat wrapped in a new active packaging system formulated with essential oils of Rosmarinus officinalis. Int. J. Food Sci. Nutr., 64(8), 921-928.

Soysal, Ç., Bozkurt, H., Dirican, E., Güçlü, M., Bozhüyük, E.D., Uslu, A.E. \& Kaya, S. (2015): Effect of antimicrobial packaging on physicochemical and microbial quality of chicken drumsticks. Food Control, 54, 294-299.

Vinci, G. \& Antonelli, M.L. (2002): Biogenic amines: Quality index of freshness in red and white meat. Food Control, 13, 519-524. 